\title{
The Impact of a Comprehensive Two Child Policy on Population and Economic Structure
}

\author{
Yinhuan Li \\ School of North China Electric Power University, Baoding 071000, China. \\ 18730217961@163.com
}

\begin{abstract}
The population problem involves the quality of population and the structure of population. It is a complex system engineering. The stable population development is directly related to the sustainable development of our society and economy. Based on the grey prediction method, this paper predicts the change of population in China under the full implementation of the two-child policy [1]. We set up a grey prediction model based on grey prediction theory to predict the total population of our country for 2017-2030 years. Economic development is constrained by factors such as capital, energy, labor and technology. According to the analysis of the data, we have determined six factors affecting the economy, such as capital input, energy consumption, labor input, population growth, technical turnover and resident consumption. The coefficient of variation is used to calculate the objective weight of the index. Finally, we conclude that population structure has great influence on the economy, and its performance is in terms of labor force. Through targeted changes in the labor force, the changes in the population of children and the impact on economic growth, we have made targeted recommendations to the policy.
\end{abstract}

Keywords: Universal two-child policy; gray prediction; Coefficient of variation.

\section{Introduction}

China is a large population country. Population problem is always one of the key factors that restrict the development of our country. With the constant change of the population and natural growth rate in China, the population development of our country has appeared some new characteristics from the initial policy of family planning to the policy of gradually releasing the birth policy to the two - child policy. For the current "marriage after 80", their fertility wishes will play a vital role in the future population growth trend in China. The population structure has changed after the change of family planning policy. 2016 is the most populous year since 2000 .

\section{Model Hypothesis}

(1) Assume that all factors that characterize and affect population changes are determined in the mean sense of the whole population.

(2) During the forecast period, the level of births and deaths is relatively stable. Even if there are changes, there are also regular patterns.

(3) Due to the prediction of the national population and the population as a whole, it is assumed that the number of floating population in China has basically been balanced in recent years.

\section{Forecasting the Total Population of Our Country in the Years 2017-2030}

The idea of grey modeling is to analyze the differential equation from the sequence angle. It is the main condition to understand its composition, and then the approximate differential equation model is established for the sequence approximately satisfying these conditions. For the sequence, the finite difference information can only be obtained. Therefore, the differential equation model is established by the sequence. In essence, the finite difference information is used to establish an infinite difference information model. $[2]:$

Access to information, we can see that the number of population satisfies the following relations 


$$
x(k+1)=[b-\mu / a] e^{-a k}-\mu / a
$$

Using the population data of China in 1999-2015, then according to the principle of the least square method and the Matlab software programming, we can get the solution of parameters: $a=0.0218, \mu$ $=0.0888, \mathrm{~b}=0.0975$.

Then the population quantity model can be obtained by substituting the result into the formula:

$$
x(k+1)=-3.0626 e^{-0.0288 k}-3.1601
$$

Through the modeling process mentioned above, we can see that the solution of the model is an exponential function. In fact, for any nonnegative discrete point sequence, the cumulative sequence of the model is exponential, so it is possible to fit the exponential function.

Finally, we get the following results:

Form 1. Forecast results of total population for 2017-2030 years

\begin{tabular}{|c|c|c|c|c|c|c|c|c|}
\hline Particular year & 2016 & 2018 & 2020 & 2022 & 2024 & 2026 & 2028 & 2030 \\
\hline Number (billion) & 13.1495 & 13.2212 & 14.2909 & 14.3587 & 14.4246 & 14.4956 & 14.5484 & 14.4025 \\
\hline
\end{tabular}

\section{Exploring the Impact of Population Structure on Economic Development}

We found the total population, male population, female population, urban population and rural population in China in the end of 1996-2015 years through web data. By drawing, we get the following figure.

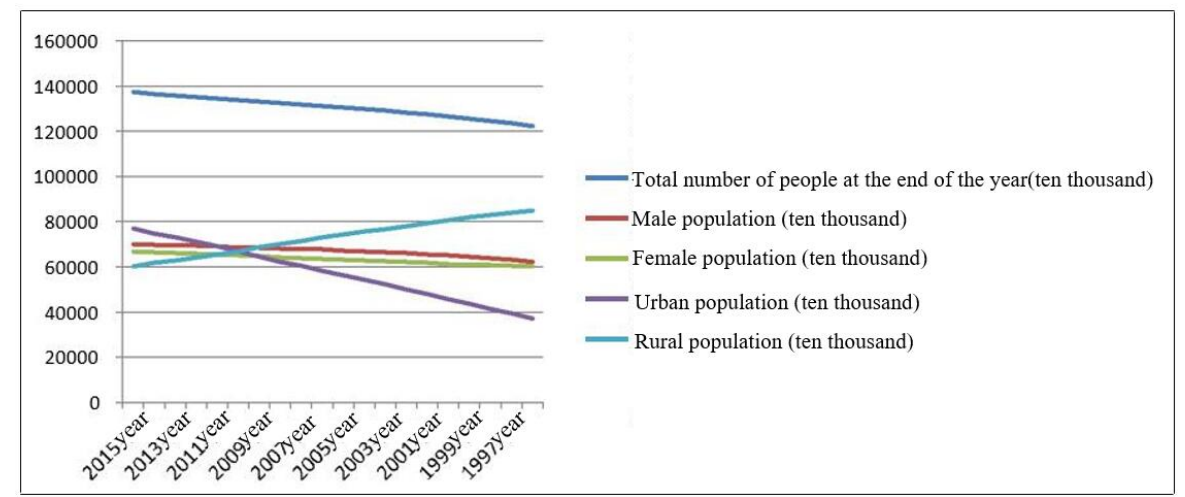

Figure 1. The changes in the population structure of China in the past 1996-2015 years

Through the analysis of Figure1, we find that: In the past 1996-2015 years, the total population of China has been on the rise, and the total number of rural population has not decreased. The number of men in the number of men and women is always more than that of women.

According to the analysis of the data to simplify the model and ignore the other minor factors, six factors that affect the economy are determined: capital input, energy consumption, labor input, population growth, technical turnover and resident consumption, and the following evaluation model is established.

Using the data of various factors over the years directly, the coefficient of variation is used to calculate the objective weight of each index in economic development: Capital investment accounts for 0.352472 , Energy consumption accounted for 0.352472 , labor input accounted for 0.352472 , population growth accounted for 0.352472 , technology turnover accounted for 0.352472 , and household consumption accounted for 0.352472 .

Through the weight of each index, we build a comprehensive index Q of economic development through weighted average which reflects the economic development of 2020-2030 years. Q is shown in the following table and the figure: 
Form 2. 2020-2030 years of economic development value Q

\begin{tabular}{|c|c|c|c|c|c|}
\hline Particular year & 2021 & 2022 & 2023 & 2024 & 2025 \\
\hline Q & 49026.27 & 57696.53 & 69822.16 & 80979.61 & 82534.51 \\
\hline Particular year & 2026 & 2027 & 2028 & 2029 & 2030 \\
\hline Q & 93929.76 & 109505.74 & 126799.78 & 149453.70 & 173603.94 \\
\hline
\end{tabular}

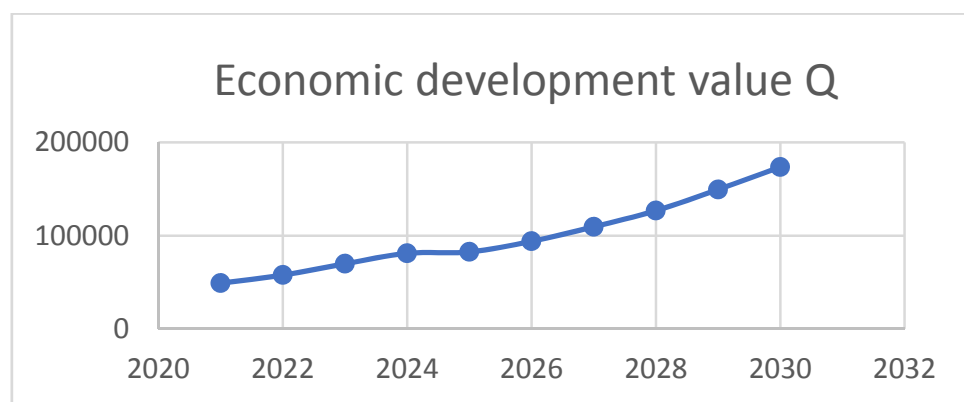

Figure 2. The trend of Q in the past 2020 2030 years

According to figure two, we can see that in the 2020-2030 years economic development is rising in a straight line, we can draw a conclusion that under the policy of full two children, the population structure in the next 2020-2030 years will play a great role in the development of the economy.

\section{Fertility Suggestion for Rationalization of Population Development}

(1) Improve the supply of labor in the future. On the basis of the "comprehensive two child" population policy, we should further adjust and relax the population birth policy as soon as possible.

(2) Tapping the existing labor supply. Under the background of the continuous decline of the labor force, we should guide full employment to transform more working age population into labor force. If we recognize the demographic dividend and its importance, we must speed up economic development so as to fully absorb the remarkable labor force.

(3) Promote more old people to recharge the labor force. We should raise the retirement age and increase the proportion of the elderly in economic activities, so as to transform the old population into the labor force.

(4) Reducing the burden of raising children and old people. We should improve the social security system, reduce the burden on the elderly and reduce the negative impact on the economy.

\section{Summary}

The grey prediction model [3] is established in this paper, and the grey prediction model is used to make a short-term prediction of China's population growth trend. The grey prediction model is to find information from its own sequence to establish a model, and to find and understand the inherent laws of the prediction, so only a small amount of data can be more accurately predicted, thus the model has a strong transplant ability.

After extensive experiments on the model, it can be seen that its accuracy is very high when making short-term forecasts.

The coefficient of variation method must take full account of the factors that affect population growth in this model and turn qualitative into quantitative ones. Considering the factors of each surface, the result is closer to reality and has higher practical value and theoretical value.

\section{References}

[1]. Deng Jian. Population forecasting and population control. Beijing, People's Publishing House. 1981. 
[2]. Zhonggeng Han. Mathematical modeling method and its corresponding. Beijing, Higher Education Press. 347-348. 2005.

[3]. Yongxia Lb, Yongcheng Lv, Jingqin Xu. Grey correlation analysis of the structure of China's population system. Journal of the Guangxi Academy of Sciences, 22. 112-115. 2006. 